\title{
p62/SQSTM1 is involved in cisplatin resistance in human ovarian cancer cells via the Keap1-Nrf2-ARE system
}

\author{
MEIHUI XIA ${ }^{1,2^{*}}$, HUIMEI YU ${ }^{3 *}$, SHUANG GU$^{4}, \mathrm{YE} \mathrm{XU}^{5}, \mathrm{JING} \mathrm{SU}^{3}$, \\ HONGYAN LI ${ }^{3}$, JINSONG KANG ${ }^{3}$ and MANHUA CUI ${ }^{1}$ \\ ${ }^{1}$ Department of Obstetrics and Gynecology, The Second Hospital of Jilin University, Changchun, \\ Jilin 130041; ${ }^{2}$ Department of Obstetrics and Gynecology, The First Hospital of Jilin University; \\ ${ }^{3}$ Department of Pathophysiology, School of Basic Medical Sciences, Jilin University; \\ ${ }^{4}$ Department of Thoracic Surgery, The People's Hospital of Jilin Province, Changchun, \\ Jilin 130021; ${ }^{5}$ Medical Research Lab, Jilin Medical College, Jilin 132013, P.R. China
}

Received June 27, 2014; Accepted August 7, 2014

DOI: 10.3892/ijo.2014.2669

\begin{abstract}
The mechanisms underlying cisplatin resistance in tumors are not fully understood. Previous studies have reported that cellular resistance to oxidative stress is accompanied by resistance to cisplatin. However, the relationship between the resistance to oxidative stress and cisplatin drug resistance in human ovarian cancer cells (HOCCs) is not clear. Here, we reveal a critical role for the multifunctional protein 662/SQSTM1 in cisplatin resistance in human ovarian cancer cells (HOCCs). p62/SQSTM1 (sequestosome 1) plays important roles in cell differentiation, proliferation and as an antiapoptotic molecule. We found that cisplatin-resistant SKOV3/DDP cells express much higher levels of p62 than do cisplatin-sensitive SKOV3 cells. The protein p62 can activate the Keap1-Nrf2-ARE signaling pathway and induce the expression of antioxidant genes in SKOV3/DDP cells. Knockdown of p62 resensitizes SKOV3/DDP cells to cisplatin. Collectively, our data indicate that cisplatin resistance in HOCCs is partially attributable to their high expression of p62, which plays an important role in preventing ROS stress-induced apoptosis by regulating the Keap1-Nrf2-ARE signaling pathway.
\end{abstract}

\section{Introduction}

Ovarian cancer is one of the deadliest gynecological malignancies, and at advanced stages is typically treated with

Correspondence to: Dr Manhua Cui, Department of Obstetrics and Gynecology, The Second Hospital of Jilin University, 218 Ziqiang Street, Changchun, Jilin 130041, P.R. China

E-mail: cuimanhua@126.com

*Contributed equally

Key words: p62/SQSTM1, Keap1-Nrf2-ARE signaling pathway, apoptosis, cisplatin, drug resistance, ovarian cancer cytoreductive surgery and platinum-based chemotherapy (1-3). However, cisplatin resistance can limit the utility of chemotherapeutic intervention (4-6). Some cancers have intrinsic resistance to cisplatin, while in others resistance gradually develops over time (6). The mechanisms underlying cisplatin resistance are not fully understood, though they are believed to be affected by multiple molecular factors, including progressive downregulation of pro-apoptotic pathways and activation of survival pathways (6). Multiple recent studies have also reported that chronic oxidative stress could lead to cisplatin resistance (7-10).

Several studies indicate that cisplatin toxicity occurs via the increased generation of reactive oxygen species (ROS) within mitochondria $(11,12)$. The Nrf2-Keap1 pathway functions as a critical regulator of cellular defense against oxidative stress by controlling the expression of many cellular protective proteins (13). Under non-stressed condition, Nrf2 is constitutively degraded through the ubiquitin-proteasome system by binding to Kelch-like ECH-associated protein 1 (Keap1), an adaptor of a ubiquitin ligase complex (14). Oxidative stress disrupts the sequestration of Nrf2 by Keap1, leading to nuclear translocation of Nrf2. Nuclear Nrf2 then binds to the cis-acting antioxidant response element (ARE) in the promoter of target genes $(14,15)$.

As a multifunctional protein, p62/SQSTM1 (sequestosome 1) plays important roles in cell differentiation, proliferation and as an antiapoptotic mediator (16,17). P62 binds to and targets ubiquitinated proteins for degradation through autophagy (18). Additionally, p62 interacts with the Nrf2 binding site on Keapl via the Keap1 binding region and functions as an activator of $\operatorname{Nrf} 2(19,20)$.

Here we describe the activation of the Keap1-Nrf2-ARE signaling pathway and subsequent induction of antioxidant gene expression in SKOV3/DDP cells by p62. We show that $\mathrm{p} 62$ possesses an important role in preventing ROS stress-induced apoptosis by regulating the Keap1-Nrf2-ARE signaling pathway, which leads to cisplatin resistance in human ovarian cancer cells (HOCCs). 


\section{Materials and methods}

Cell lines. Cisplatin-sensitive ovarian cancer cells SKOV3 and their cisplatin-resistant clones SKOV3/DDP were obtained from the Chinese Academy of Medical Sciences and Peking Union Medical College. Cells were cultured at $37^{\circ} \mathrm{C}$ with $5 \% \mathrm{CO}_{2}$ in RPMI-1640 culture medium (Gibco, Carlsbad, CA, USA), supplemented with $10 \%$ fetal bovine serum (Invitrogen, Carlsbad, CA, USA). Cisplatin-resistant SKOV3/DDP cells were maintained in medium containing $1 \mu \mathrm{g} / \mathrm{ml}$ cisplatin (Sigma-Aldrich, St. Louis, MO, USA) to maintain resistance.

Cell viability assays. The MTT assay was used to measure cell viability. Cells were plated at $1 \times 10^{4}$ cells per well in 96-well plates. The following day, indicated concentrations of cisplatin or $\mathrm{H}_{2} \mathrm{O}_{2}$ were added, and incubation proceeded for the specified times. Each treatment was conducted in triplicate at a minimum. To each well, $20 \mu$ l MTT [3-(4,5-dimethylthiazol2-yl)-2, 5-diphenyltetrazolium bromide; (Sigma-Aldrich)], was added followed by incubation for $4 \mathrm{~h}$ and addition of $150 \mu \mathrm{l}$ dimethylsulfoxide to dissolve the formazan crystals. Absorbance was measured with a $V_{\max }$ Microplate Reader (Molecular Devices, Sunnyvale, CA, USA) at a wavelength of $570 \mathrm{~nm}$.

Measurement of intracellular reactive oxygen species. To determine the intracellular levels of ROS generated by cisplatin, we used dichlorodihydrofluorescein diacetate (DCFH-DA), which is cell-permeable and interacts with intracellular ROS to generate fluorescent dichlorofluorescin as reported previously (21). Cells were plated at $1 \times 10^{4}$ cells per well in 96-well plates, and cultured with cisplatin or $\mathrm{H}_{2} \mathrm{O}_{2}$ for 12 or $24 \mathrm{~h}$. After this preincubation period, the medium was discarded and the attached cells were rinsed thrice with phosphate-buffered saline (PBS). Cells were then exposed to $5 \mu \mathrm{M}$ DCFH-DA solution for $15 \mathrm{~min}$ at $37^{\circ} \mathrm{C}$. The treated cells were washed three times with PBS. The cells were subsequently scanned to quantitate the average fluorescence intensity per cell.

Immunofluorescence staining and confocal laser microscopy. Apoptotic nuclear changes were assessed with Hoechst 33342 (Sigma-Aldrich). Following treatment with $1 \mathrm{mM} \mathrm{H}_{2} \mathrm{O}_{2}$ for 0 and $24 \mathrm{~h}$, cells were fixed in $4 \%$ paraformaldehyde, stained with Hoechst $33342(2 \mu \mathrm{g} / \mathrm{ml})$ for $30 \mathrm{~min}$, washed with PBS, and examined using an Olympus FV1000 confocal laser microscope. Cells were cultured on coverslips overnight, treated with $1 \mathrm{mM} \mathrm{H}_{2} \mathrm{O}_{2}$ for different times, and rinsed with PBS. After incubation, cells were fixed for $20 \mathrm{~min}$ in $4 \%$ paraformaldehyde, permeabilized with $0.1 \%$ Triton X-100 for $5 \mathrm{~min}$, blocked with bovine serum albumin, incubated with primary antibodies against p62 and Keap1 overnight at $4{ }^{\circ} \mathrm{C}$, and then FITC/Texas-conjugated secondary antibodies (1:400 dilution; all antibodies were from, Santa Cruz Biotechnology, Santa Cruz, CA, USA) for $1 \mathrm{~h}$. Cells were examined by confocal laser microscopy.

RNA extraction and reverse-transcriptase PCR. Total RNA was extracted from cells using TRIzol reagent (Invitrogen) according to the manufacturer's protocol. First-strand cDNA synthesis was performed by reverse transcription of
RNA samples using the SuperScript preamplification system (Promega, Madison, WI, USA). Absolute gene transcription was normalized to glyceraldehyde-3 phosphate dehydrogenase (GAPDH). Primers for GAPDH: sense strand: 5'-GGG-TGATGC-TGG-TGC-TGA-GTA-TGT-3', antisense strand: 5'-AAGAAT-GGG-AGT-TGC-TGT-TGA-AGT-3'. Primers for p62: sense strand: 5'-GAA-CTC-CAG-TCC-CTA-CAG-AT-3', antisense strand: 5'-CGA-TGT-CAT-AGT-TCT-TGG-TC-3'. PCR products were separated on a $1 \%$ agarose gel containing ethidium bromide, visualized using a Tanon-1600 figure gel image processing system, and analyzed by GIS 1D gel image system software (Tanon, Shanghai, China).

Western blot analysis. Cells were harvested following the various treatments described above, washed with cold PBS, and incubated in ice-cold radio-immunoprecipitation buffer. Cell lysates were sonicated for $30 \mathrm{sec}$ on ice and then incubated at $4^{\circ} \mathrm{C}$ for $60 \mathrm{~min}$. Lysates were then centrifuged for $30 \mathrm{~min}$ at $12,000 \mathrm{~g}$ to remove debris. Protein concentration was determined using the Protein Assay kit (Bio-Rad, Hercules, CA, USA). For western blot analysis, protein lysates (30-50 $\mu \mathrm{g})$ were separated on a $12 \% \mathrm{w} / \mathrm{v}$ SDS-polyacrylamide gel by electrophoresis and transferred onto nitrocellulose membranes (Millipore, Bedford, MA, USA). Membranes were blocked with $5 \%$ non-fat dry milk in buffer $[10 \mathrm{mM}$ Tris- $\mathrm{HCl}$ (pH 7.6), $100 \mathrm{mM} \mathrm{NaCl}$, and $0.1 \%$ Tween-20] for $1 \mathrm{~h}$ at room temperature, incubated with the desired primary antibody overnight at $4^{\circ} \mathrm{C}$, and then incubated with horseradish peroxidase-conjugated secondary antibody (Thermo, Waltham, MA, USA) at a 1:2,000 dilution for $1 \mathrm{~h}$ at room temperature. Immunoreactive bands were visualized using the diaminobenzene (Sigma) coloration method.

p62 knockdown by small interfering RNA. Small interfering RNA (siRNA) sequences targeting human p62/SQSTM1 (GenBank accession NM_003900) and a scrambled nontargeting control sequence were constructed by Genechem (Shanghai, China). Described previously, the p62 siRNA (si-p62) sequence was GAC-ATC-TTC-CGA-ATC-TAC-A, and that of the control siRNA (Scramble) was TTC-TCCGAA-CGT-GTC-ACG-T (18). Transfection with siRNA was performed using Lipofectamine 2000 (Invitrogen) according to the manufacturer's protocol. Briefly, cisplatin-resistant SKOV3/DDP cells were seeded into 6-well plates, and transfected the next day with si-p62 or si-Scramble. Cells were harvested 2 days post-transfection, and whole cell lysates were prepared for western blots. For the MTT assay, transfected cells were treated with different concentrations of $\mathrm{H}_{2} \mathrm{O}_{2}$ for $24 \mathrm{~h}$ and subjected to the MTT assay to determine cell viability.

Flow cytometry. Following exposure to different experimental conditions, cells were trypsinized and incubated with propidium iodide (PI, $1 \mu \mathrm{g} / \mathrm{ml})$ and Annexin V-FITC $(1 \mu \mathrm{g} / \mathrm{ml}$; Invitrogen) for $15 \mathrm{~min}$ at $37^{\circ} \mathrm{C}$. Samples were then analyzed for apoptosis using a FACScan flow cytometer (Becton-Dickinson, Franklin Lakes, NJ, USA).

Analysis of luciferase reporter gene activity. The DualLuciferase Reporter Assay System (Promega) was used to examine reporter gene activity. Cells were plated at $1 \times 10^{5}$ per 


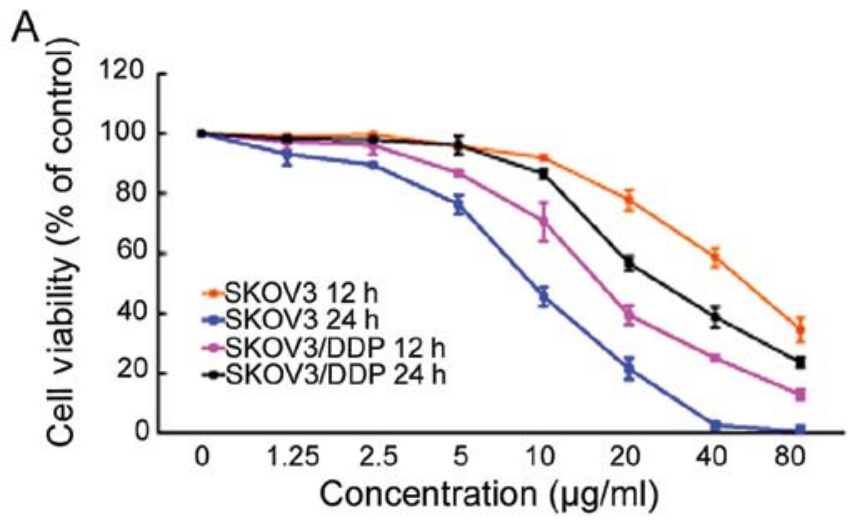

B
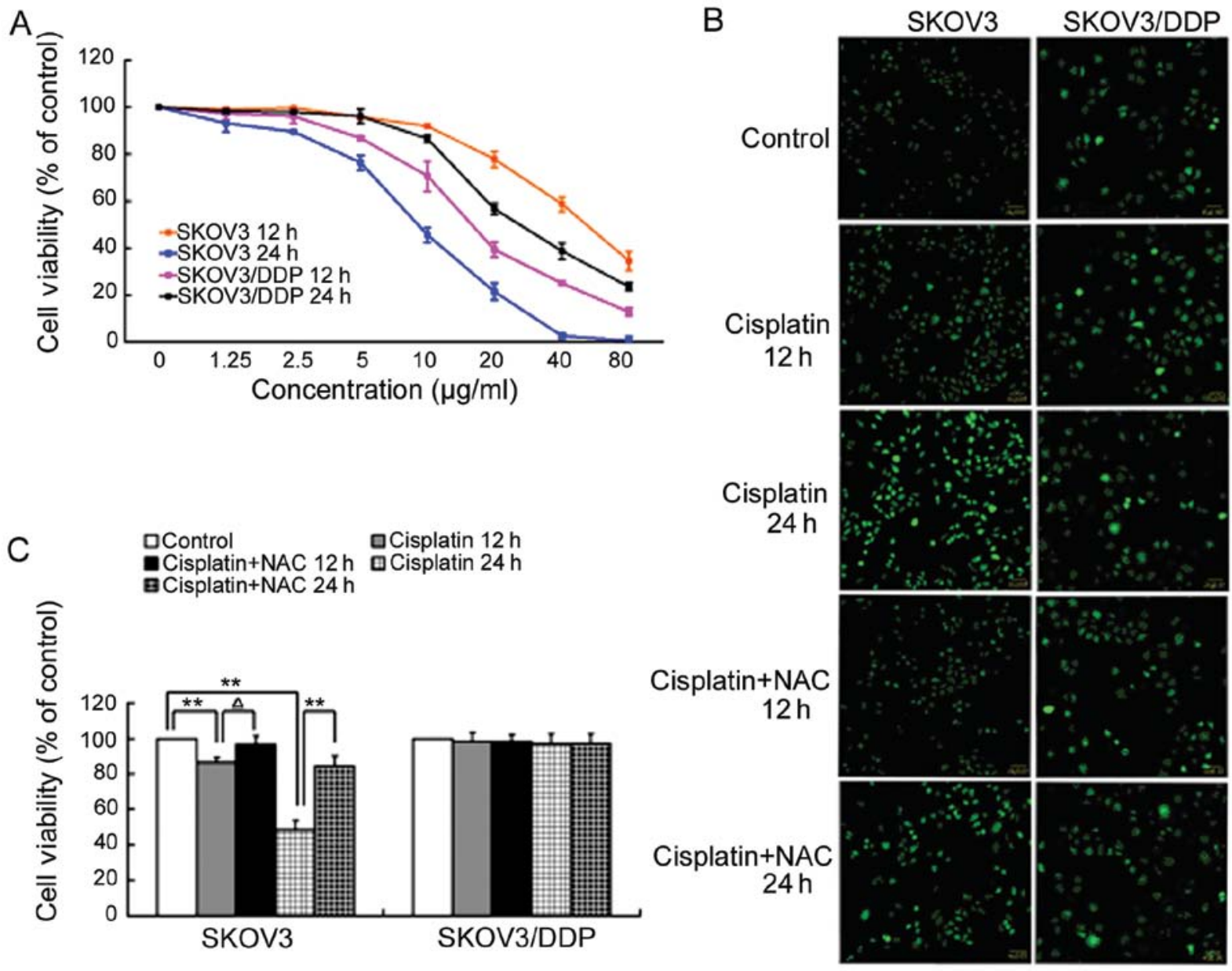

Figure 1. Cisplatin inhibits the growth and induces ROS in HOCCs. (A) SKOV3 and SKOV3/DDP cells were treated with increasing doses of cisplatin for 12 and $24 \mathrm{~h}$. Cell viability was determined by MTT assay. Data are presented as mean $\pm \mathrm{SD}, \mathrm{n}=3$. (B) Cells were treated with $6 \mu \mathrm{g} / \mathrm{ml}$ cisplatin for 12 and $24 \mathrm{~h}$, stained with DCFH-DA $(10 \mu \mathrm{M})$. Cell morphology was observed by fluorescence microscopy (bar, $50 \mu \mathrm{m})$. (C) Cells were treated with $6 \mu \mathrm{g} / \mathrm{ml}$ cisplatin and/ or NAC for 12 and $24 \mathrm{~h}$. Cell viability was determined by MTT assay. Data are presented as mean $\pm \mathrm{SD}, \mathrm{n}=3 .{ }^{*} \mathrm{p}<0.05$, $^{* *} \mathrm{p}<0.01$.

well in 24-well plates. The next day, the cells were transiently transfected with various ARE-luciferase reporter plasmids using Lipofectamine 2000 reagent. Following transfection, cells were incubated for 0,4 , and $8 \mathrm{~h}$ in medium containing $\mathrm{H}_{2} \mathrm{O}_{2}$ and then harvested.

The luciferase activity present in lysates was measured using a luminometer following addition of Luciferase Assay Reagent II. The relative luciferase activity was calculated by normalizing firefly luciferase activity to that of Renilla luciferase.

Statistical analyses. Experiments were performed on at least three occasions, and are presented as the means \pm SD. Comparisons were made between treatments using paired Student's t-test, or one-way ANOVA for multiple group comparisons to single controls; differences between treatment means were examined with Dunnett's test. We used SPSS version 16.0 (SPSS/IBM, Chicago, IL, USA). " p $<0.05$ was considered statistically significant.

\section{Results}

Cisplatin induces ROS generation and inhibits growth in ovarian cancer cells. Cisplatin-sensitive SKOV3 cells and cisplatin-resistant SKOV3/DDP cells were treated with increasing doses of cisplatin for $12 \mathrm{~h}$ and $24 \mathrm{~h}$ and examined for growth inhibition using MTT assays. While cisplatin inhibited the growth of both cell lines, SKOV3 cells were more sensitive to cisplatin than SKOV3/DDP cells (Fig. 1A).

Based on these MTT results and previous studies (18), we next treated both cell lines with $6 \mu \mathrm{g} / \mathrm{ml}$ cisplatin for 12 and $24 \mathrm{~h}$ and then used DCFH-DA to measure hydrogen peroxide levels by fluorescent confocal microscopy. ROS levels increased significantly in SKOV3 cells treated with $6 \mu \mathrm{g} / \mathrm{ml}$ cisplatin after 12 and $24 \mathrm{~h}$. When cisplatin treatment was combined with the antioxidant $\mathrm{N}$-acetylcysteine (NAC; $80 \mu \mathrm{M})$, the intracellular ROS level did not increase and was similar to the control group. ROS levels underwent no significant change in SKOV3/DDP cells treated with $6 \mu \mathrm{g} / \mathrm{ml}$ cisplatin after 12 or $24 \mathrm{~h}$ (Fig. 1B).

Additionally, the MTT assay showed that the cell survival rate was significantly improved when cisplatin treatment was combined with NAC relative to cisplatin treatment alone. There was no similar effect in SKOV3/DDP cells treated with cisplatin and NAC (Fig. 1C).

$\mathrm{H}_{2} \mathrm{O}_{2}$ inhibits growth and induces apoptosis in ovarian cancer cells. We then treated SKOV3 and SKOV3/DDP cells 


\section{A}

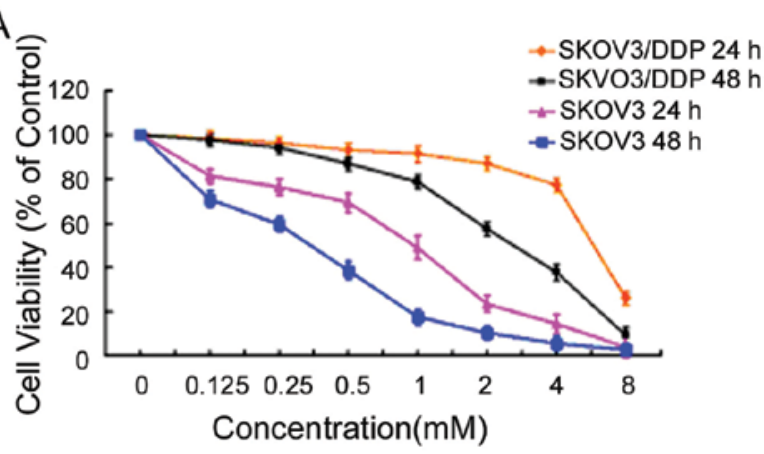

C

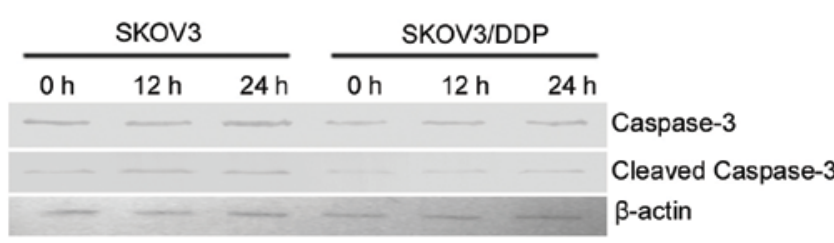

B

SKOV3
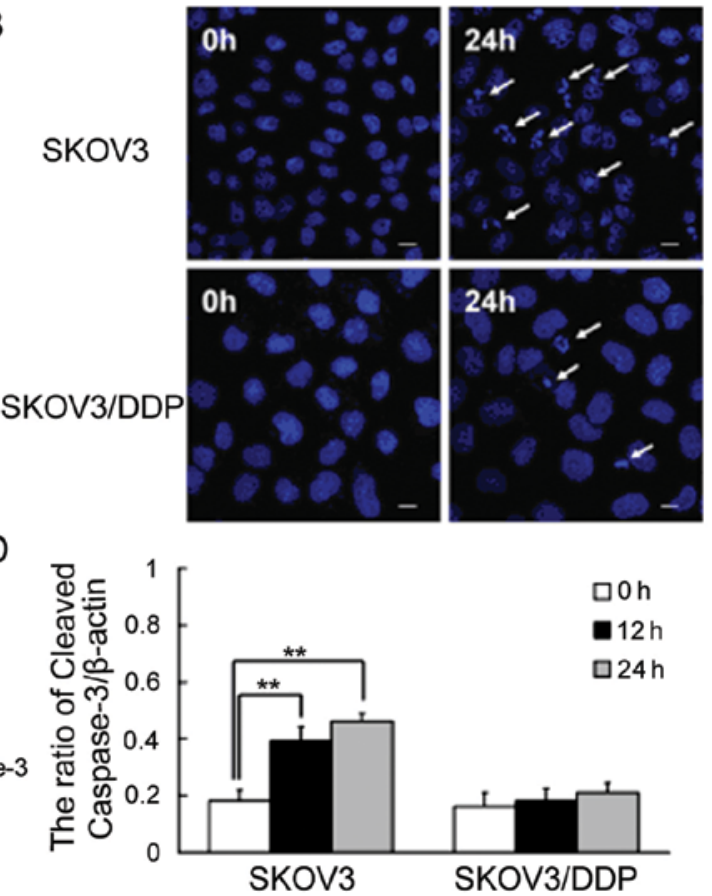

Figure 2. $\mathrm{H}_{2} \mathrm{O}_{2}$ inhibits growth and induces apoptosis in HOCCs. (A) SKOV3 and SKOV3/DDP cells were treated with increasing doses of $\mathrm{H}_{2} \mathrm{O}_{2}$ for 24 and $48 \mathrm{~h}$. Cell viability was determined by MTT assay. Data are presented as a mean $\pm \mathrm{SD}, \mathrm{n}=3$. (B) Cells were treated with $1 \mathrm{mM} \mathrm{H}_{2} \mathrm{O}_{2}$ for $24 \mathrm{~h}$, stained with Hoechst 33342. Cell morphology was observed by confocal microscopy (bar, $20 \mu \mathrm{m}$ ). (C) Western blot analysis for the expression of caspase-3 and cleaved caspase-3 protein in SKOV3 and SKOV3/DDP cells treated with $1 \mathrm{mM} \mathrm{H}_{2} \mathrm{O}_{2}$. (D) Quantitation of cleaved caspase-3 protein level. Data are presented as mean $\pm \mathrm{SD}, \mathrm{n}=3 .{ }^{* *} \mathrm{p}<0.01$.
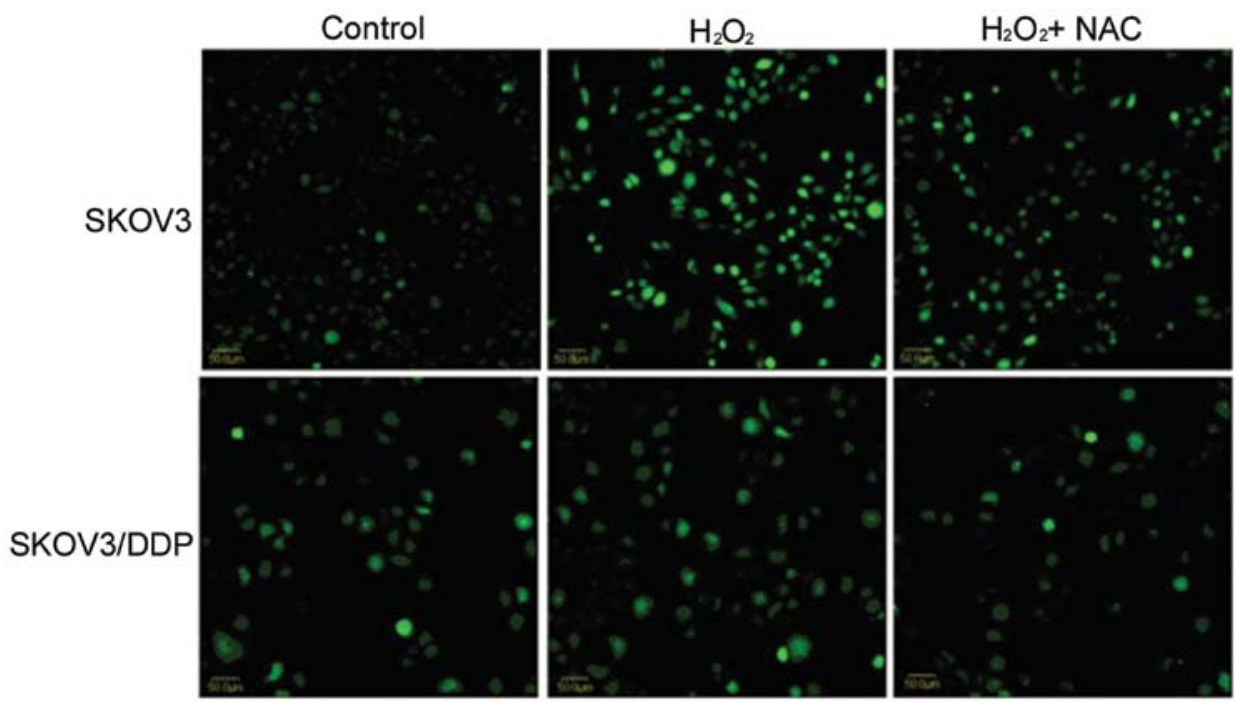

Figure 3. $\mathrm{H}_{2} \mathrm{O}_{2}$ induces apoptosis in HOCCs. SKOV3 and SKOV3/DDP cells were treated with $1 \mathrm{mM} \mathrm{H}_{2} \mathrm{O}_{2}$ for $4 \mathrm{~h}$ and stained with DCFH-DA (10 $\left.\mu \mathrm{M}\right)$. Cell morphology was observed by confocal microscopy (bar, $50 \mu \mathrm{m})$.

with increasing doses of $\mathrm{H}_{2} \mathrm{O}_{2}$ for 24 and $48 \mathrm{~h}$ and measured growth inhibition using the MTT assay. While $\mathrm{H}_{2} \mathrm{O}_{2}$ inhibited the growth of both cell lines, SKOV3 cells were more sensitive to $\mathrm{H}_{2} \mathrm{O}_{2}$ than SKOV3/DDP cells (Fig. 2A).

Based on these MTT results, we next treated both cell lines with $1 \mathrm{mM} \mathrm{H}_{2} \mathrm{O}_{2}$, and examined apoptotic chromatin condensation with Hoechst 33342 staining by fluorescence microscopy (Fig. 2B). Compared with controls at $24 \mathrm{~h}, \mathrm{H}_{2} \mathrm{O}_{2}$ induced apoptotic chromatin condensation was obvious in cisplatin-sensitive SKOV3 cells, but rare in cisplatin-resistant
SKOV3/DDP cells. The effect on apoptosis was assessed through measurement of caspase-3 activation by western blotting with an antibody that specifically recognizes cleaved caspase- $3 . \mathrm{H}_{2} \mathrm{O}_{2}$ enhanced the expression of cleaved caspase-3 in SKOV3 cells at 12 and $24 \mathrm{~h}$ (Fig. 2C and D). These results indicate that $\mathrm{H}_{2} \mathrm{O}_{2}$ can efficiently induce apoptosis in SKOV3 cells but not in SKOV3/DDP cells.

$\mathrm{H}_{2} \mathrm{O}_{2}$ induces $\mathrm{ROS}$ in ovarian cancer cells. To evaluate the ROS level in HOCCs treated with $\mathrm{H}_{2} \mathrm{O}_{2}$, DCFH-DA was 
A

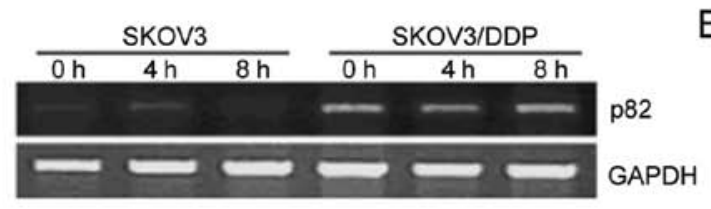

B

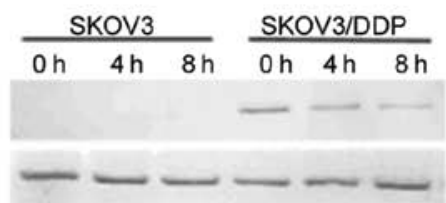

p62

$\beta$-actin
C

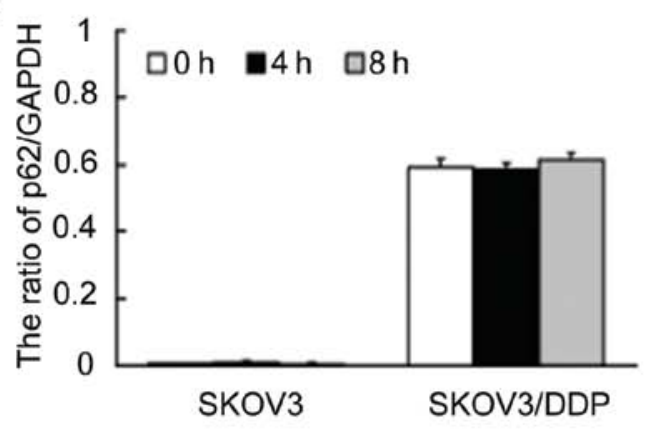

E

$\mathrm{Oh}$
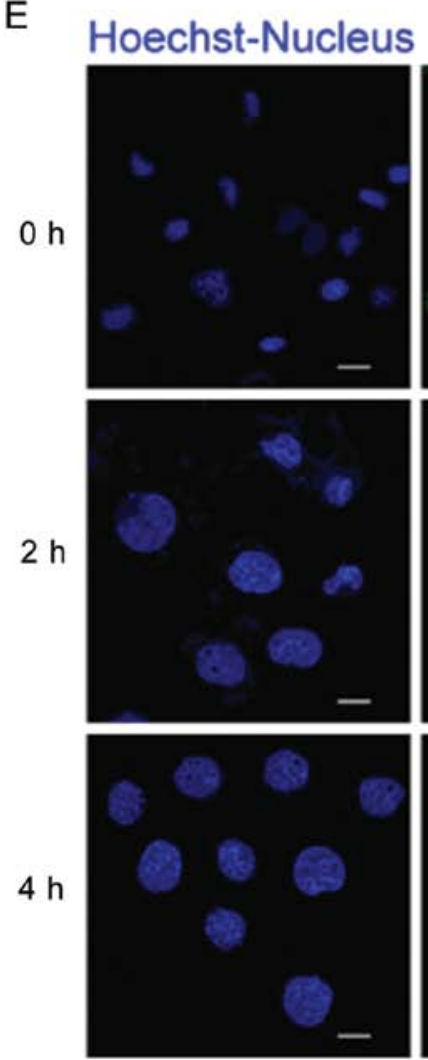
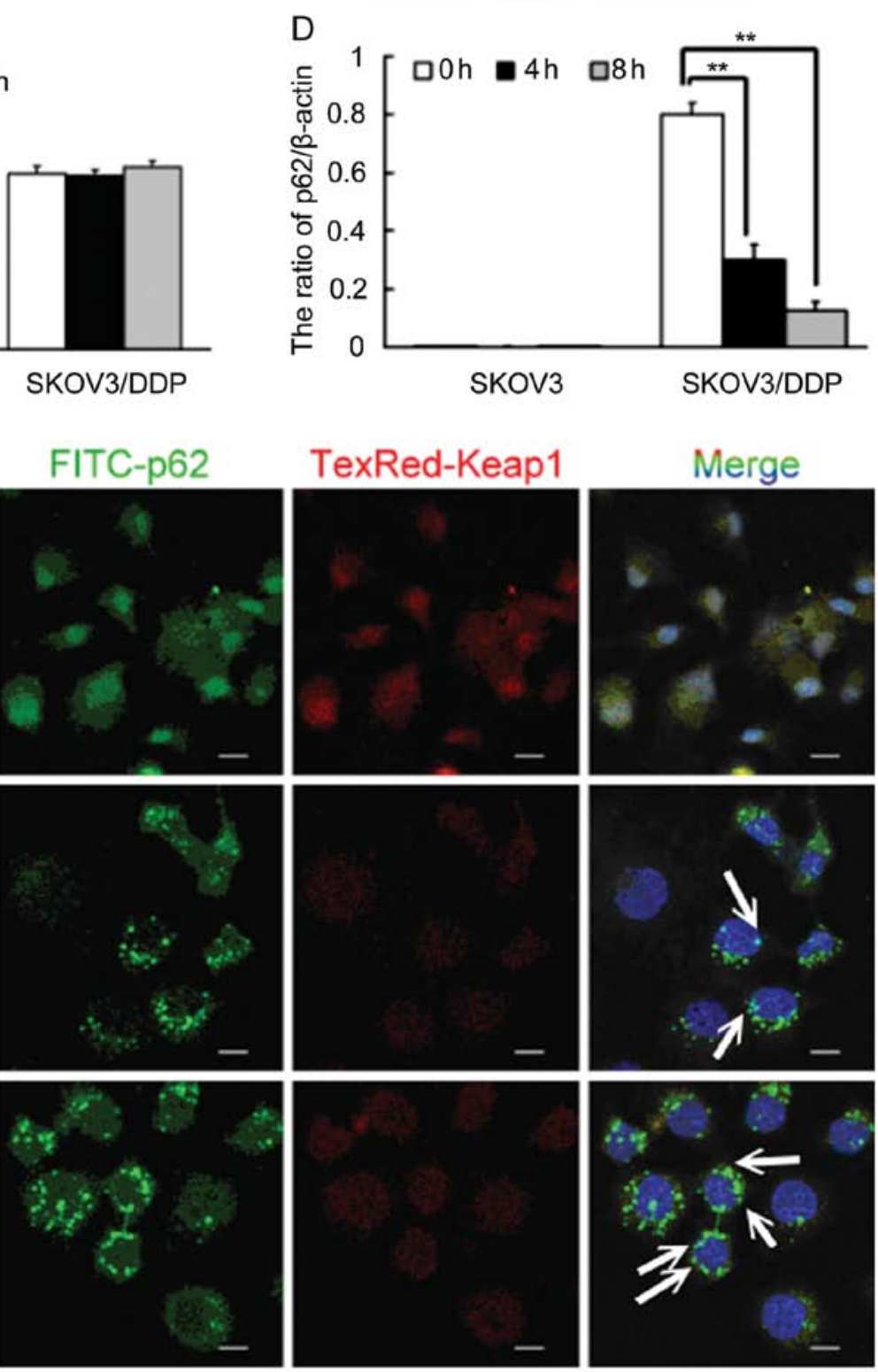

Figure 4. The expression of p62 in SKOV3 and SKOV3/DDP cells treated with $\mathrm{H}_{2} \mathrm{O}_{2}$. (A) RT-PCR analysis for the mRNA expression of p62 in SKOV3 and SKOV3/DDP cells treated with $1 \mathrm{mM} \mathrm{H}_{2} \mathrm{O}_{2}$. (B) Western blot analysis for the protein expression of p62 in SKOV3 and SKOV3/DDP cells treated with $1 \mathrm{mM}$ $\mathrm{H}_{2} \mathrm{O}_{2}$. (C) Quantitation of p62 mRNA expression. Data are presented as mean $\pm \mathrm{SD}, \mathrm{n}=3$. (D) Quantitation of p62 protein. Data are presented as mean \pm SD, $\mathrm{n}=3$. ${ }^{*} \mathrm{p}<0.01$. (E) The colocalization of p62 and Keap1 in SKOV3/DDP cells treated with $1 \mathrm{mM} \mathrm{H}_{2} \mathrm{O}_{2}$ for 2 and 4 h (bar, $10 \mu \mathrm{m}$; arrows, the colocalization of p62 and Keap1).

employed. After 4-h treatment, $\mathrm{H}_{2} \mathrm{O}_{2}$ was shown to induce ROS in SKOV3 cells, but not in SKOV3/DDP cells. Furthermore, in combination with NAC, the ROS level was decreased in SKOV3 cells (Fig. 3).

Cisplatin-resistant SKOV3/DDP cells express the highest level of $p 62$. Based on our previous studies, cisplatin-resistant SKOV3/DDP cells express much higher levels of p62 than do cisplatin-sensitive SKOV3 cells. As a multifunctional protein, p62 has been reported to recruit ubiquitinated proteins to autophagosomes for degradation, and also to regulate the Keap1-Nrf2-ARE system in cancer cells. We next determined the expression levels of p62 protein and mRNA after $\mathrm{H}_{2} \mathrm{O}_{2}$ mediated ROS induction in HOCCs. Following a 4-h treatment with $1 \mathrm{mM} \mathrm{H}_{2} \mathrm{O}_{2}$, p62 protein levels in SKOV3/DDP cells decreased gradually while p62 mRNA transcripts remained constant. This indicates that $\mathrm{H}_{2} \mathrm{O}_{2}$ decreases p62 at the protein level (Fig. 4A-D).

Following both 2- and 4-h treatment of SKOV3/DDP cells with $\mathrm{H}_{2} \mathrm{O}_{2}$, p62 levels increased while Keap1 levels decreased. 

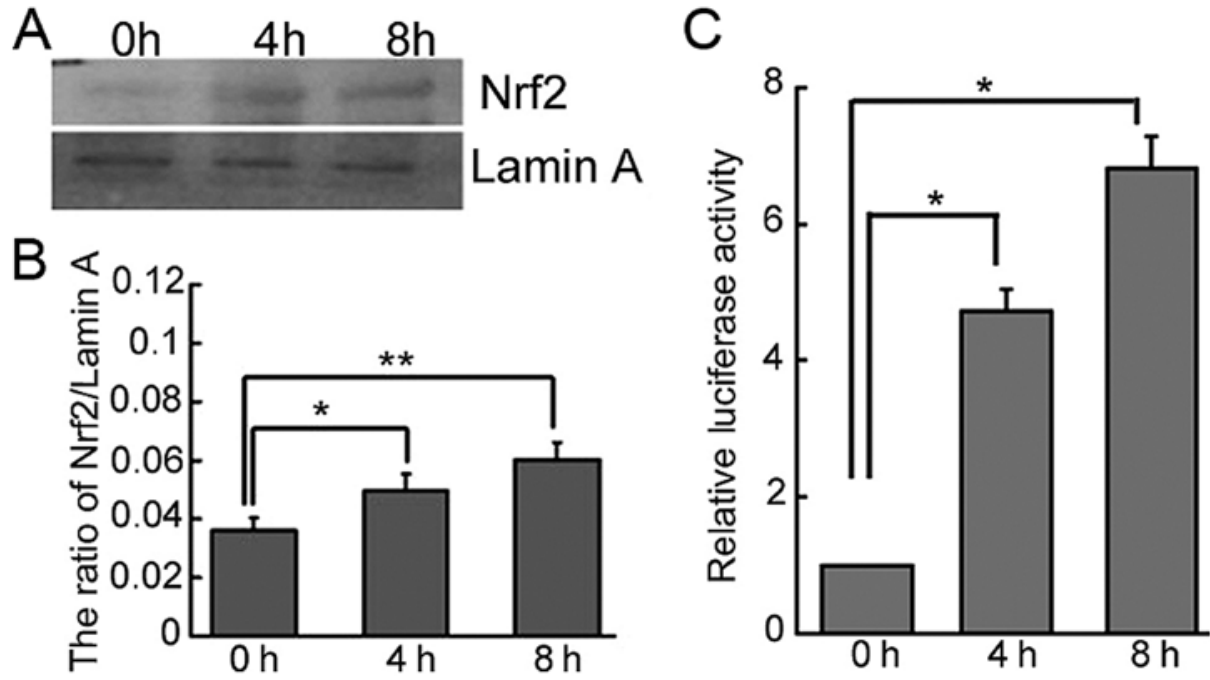

Figure 5. $\mathrm{H}_{2} \mathrm{O}_{2}$ induces reporter gene activity in SKOV3/DDP cells. (A) Western blot analysis for the protein expression of Nrf2 in nuclear in SKOV3/DDP cells treated with $1 \mathrm{mM} \mathrm{H}_{2} \mathrm{O}_{2}$. (B) Quantitation of $\mathrm{Nrf} 2$ proteins level. Data are presented as mean $\pm \mathrm{SD}, \mathrm{n}=3$. ${ }^{*} \mathrm{p}<0.05,{ }^{* *} \mathrm{p}<0.01$. (C) Cells were plated at $1 \mathrm{x} 10^{5}$ cells per well in 24-well plates, transfected with the various pGL3-nxARE constructs, and treated with $1 \mathrm{mM} \mathrm{H}_{2} \mathrm{O}_{2}$. Luciferase reporter activity was determined after $18 \mathrm{~h}$. Each treatment in each experiment has at least three replicates. Data are presented as mean $\pm \mathrm{SD}, \mathrm{n}=3$.

A

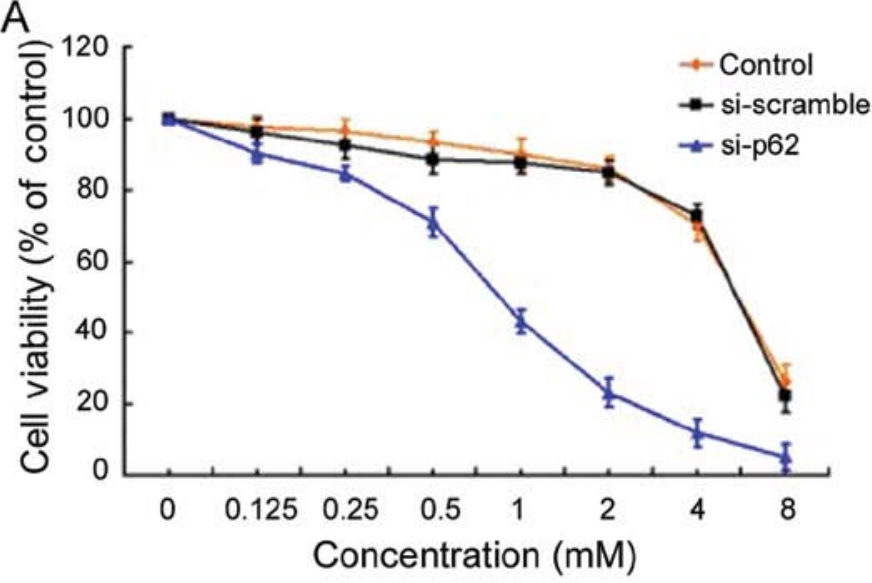

C

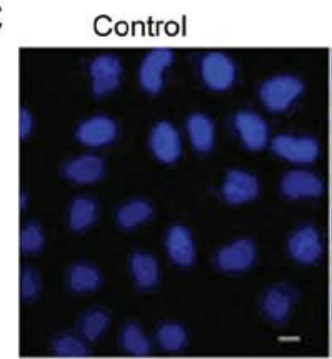

si-scramble

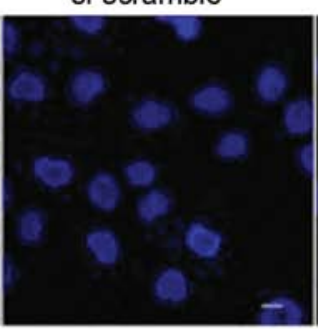

si-scramble $+\mathrm{H}_{2} \mathrm{O}_{2}$

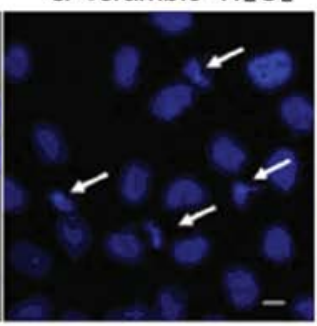

$\mathrm{D}$
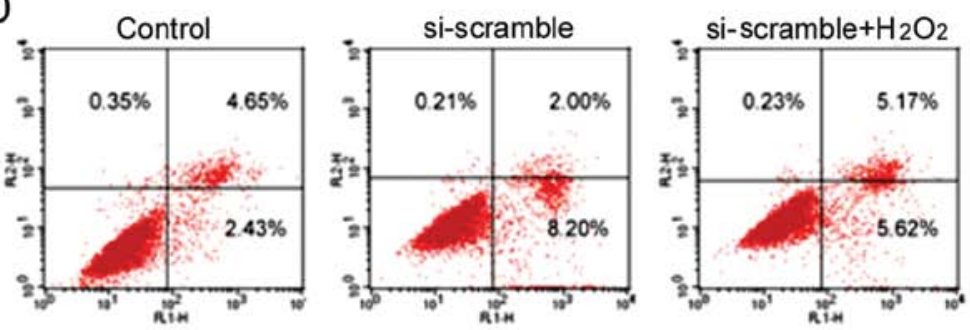

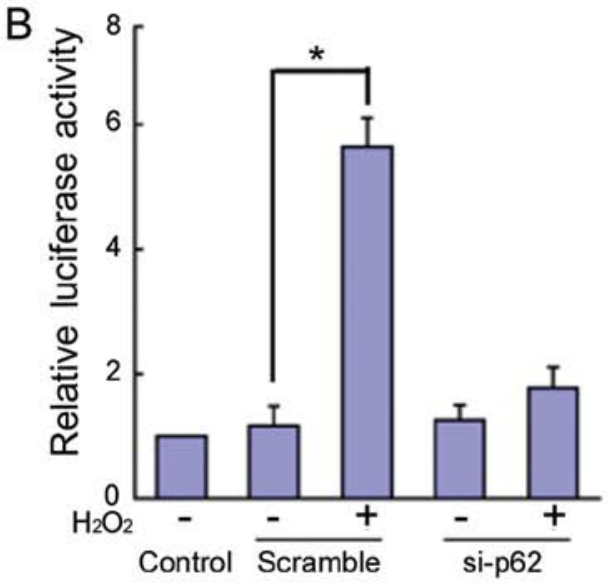

si-p62

si-p $62+\mathrm{H}_{2} \mathrm{O}_{2}$
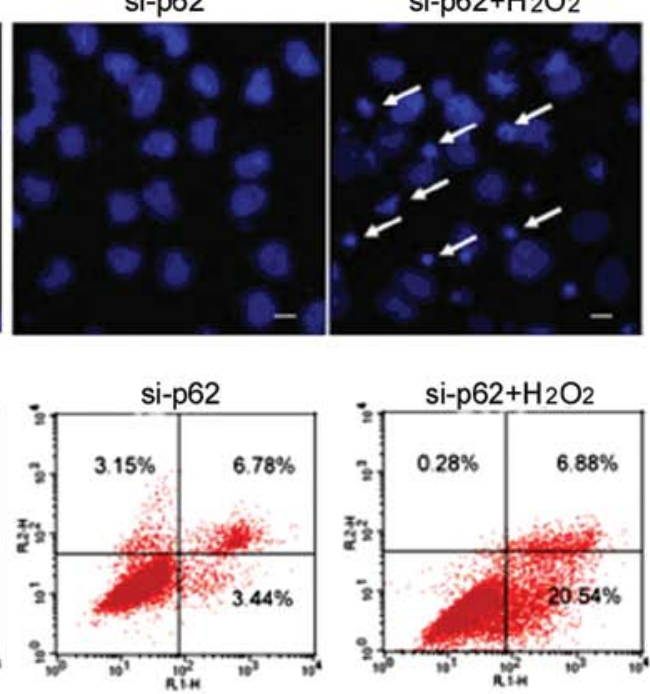

Figure 6. Knockdown of $\mathrm{p} 62$ increases $\mathrm{H}_{2} \mathrm{O}_{2}$-induced cell death in SKOV3/DDP cells. (A) Transfected SKOV3/DDP cells treated with varying doses of $\mathrm{H}_{2} \mathrm{O}_{2}$ for $24 \mathrm{~h}$. Cell viability was determined by MTT assay. Data are presented as mean $\pm \mathrm{SD}, \mathrm{n}=3$. (B) Luciferase reporter activity was determined after $18 \mathrm{~h}$. Each treatment in each experiment has at least three replicates. Data are presented as mean $\pm \mathrm{SD}, \mathrm{n}=3$. " $\mathrm{p}<0.05$. (C) Transfected SKOV3/DDP cells treated with $\mathrm{H}_{2} \mathrm{O}_{2}$ for $24 \mathrm{~h}$, stained with Hoechst 33342. Cell morphology was observed by confocal microscopy (bar, $20 \mu \mathrm{m}$ ). (D) Transfected SKOV3/DDP cells were treated with $1 \mathrm{mM} \mathrm{H}_{2} \mathrm{O}_{2}$ for $24 \mathrm{~h}$, and then stained with PI and Annexin V-FITC. Positively stained cells were counted using FACScan. Data are presented as mean $\pm \mathrm{SD}, \mathrm{n}=3$. 
We then used confocal microscopy to identify the locations of p62 and Keap1 in these cells, and observed colocalization of p62 and Keap1 in the cytosol. This suggests that p62 may interact with Keap1 in SKOV3/DDP cells (Fig. 4E).

p62 induces the Keapl-Nrf2-ARE system to reduce the ROS in resistant cells. The importance of the Keap1-Nrf2-ARE system in the cellular response to oxidative stress has been well established (22). The next step was therefore to determine whether the antioxidant gene Nrf2 was activated in cisplatin-resistant SKOV3/DDP cells treated with $\mathrm{H}_{2} \mathrm{O}_{2}$. When treated with $1 \mathrm{mM} \mathrm{H}_{2} \mathrm{O}_{2}$ over a time course, the level of Nrf2 protein gradually increased in the nucleus of SKOV3/DDP cells (Fig. 5A and B). Additionally, an ARE-luciferase reporter construct was employed to determine the response of ARE-containing genes to ROS in SKOV3/DDP cells. Here, $\mathrm{H}_{2} \mathrm{O}_{2}$ significantly increased luciferase activity (Fig. 5C).

Knockdown of p62 resensitizes cisplatin-resistant SKOV3/DDP cells to $\mathrm{H}_{2} \mathrm{O}_{2}$. To investigate the direct role of p62 in cisplatin resistance, we used siRNA to knock down p62 expression. We transfected cisplatin-resistant SKOV3/ DDP cells with siRNA against p62 or with a non-targeting scrambled sequence. Compared with the cells transfected with scrambled siRNA, p62 knockdown increased $\mathrm{H}_{2} \mathrm{O}_{2}$-induced growth inhibition in cisplatin-resistant SKOV3/DDP cells (Fig. 6A). The ARE-luciferase reporter system revealed that the reporter could not be activated by $1 \mathrm{mM} \mathrm{H}_{2} \mathrm{O}_{2}$ (Fig. 6B). Hoechst 33342 staining and confocal microscopy was used to detect apoptosis in the si-p62-SKOV3/DDP cells. Compared with controls at $24 \mathrm{~h}, \mathrm{H}_{2} \mathrm{O}_{2}$-induced apoptotic chromatin condensation was clearly observed in si-p62 SKOV3/DDP cells, but rarely in si-Scramble SKOV3/DDP cells (Fig. 6C).

Additionally, si-p62-SKOV3/DDP cells were subjected to PI and Annexin V-FITC staining followed by flow cytometry analysis to quantify apoptotic cell populations. After $24-\mathrm{h}$ incubation following treatment with $1 \mathrm{mM} \mathrm{H}_{2} \mathrm{O}_{2}, 10.79 \%$ of si-Scramble SKOV3/DDP cells and $27.42 \%$ of sip62SKOV3/DDP cells underwent apoptosis. This difference was significant (p<0.05; Fig. 6D).

\section{Discussion}

Cisplatin is one of the major chemotherapeutic drugs used in the treatment of various human cancers. Still, the mechanisms by which it induces apoptosis are not fully understood $(23,24)$. Nevertheless, acquired resistance to cisplatin limits its use. While approximately $70 \%$ of ovarian cancer patients respond to cisplatin initially, most relapse as resistance to cisplatin develops $(25,26)$. An improved understanding of the detailed mechanisms underlying cisplatin resistance is therefore critical.

The cell possesses various defenses to protect against oxidant insult from ROS and xenobiotic toxicants (27). Nrf2 is a key transcriptional regulator implicated in protecting cells against oxidative and xenobiotic stresses (21). Nrf2 has emerged as the master regulator of a cellular defense mechanism that elicits an adaptive response and promotes cell survival under stress through transcriptional activation of an array of ARE-bearing genes, including detoxifying genes, drug transporters, and cellular redox regulators. High constitutive expression of Nrf2 is observed in many cancer cells that demonstrate resistance to anticancer drugs (28). Nrf2 promotes cancer cell survival under therapeutic regimens and thus contributes to chemoresistance. In this study, we have also implicated Nrf2 in cisplatin resistance in HOCCs.

Our early studies showed that p62 binds and targets ubiquitinated proteins for degradation through autophagy, thus maintaining cellular homeostasis and contributing to cisplatin resistance in HOCCs. Herein, we demonstrated that oxidative stress tolerance may also contribute to cisplatin resistance in ovarian cancer. We found that cisplatin-resistant SKOV3/DDP cells express much higher p62 levels than do cisplatin-sensitive SKOV3 cells. Following treatment with $\mathrm{H}_{2} \mathrm{O}_{2}$, the level of p62 decreased gradually in SKOV3/DDP cells. Furthermore, confocal microscopy revealed that p62 increased while Keap1 decreased in SKOV3/DDP cells. Thus, the multifunctional protein p62 exerts its important role in drug resistance through multiple avenues, including recruitment of ubiquitinated proteins to autophagosomes for degradation, and the regulation of the Keap1-Nrf2-ARE system.

Our study reveals that p62 knockdown significantly enhances the sensitivity of cisplatin-resistant SKOV3/DDP cells to $\mathrm{H}_{2} \mathrm{O}_{2}$. Knockdown of p62 reduced the activity of the ARE in SKOV3/DDP cells, resulting in apoptosis. This indicates that p62 plays an important role in cisplatin-resistant HOCCs.

In conclusion, we have identified much higher p62 levels in cisplatin-resistant SKOV3/DDP cells compared with cisplatinsensitive SKOV3 cells. Furthermore, p62 underwent gradual degradation in SKOV3/DDP cells treated with $\mathrm{H}_{2} \mathrm{O}_{2}$, and p62 knockdown resensitizes cisplatin-resistant SKOV3/DDP cells to $\mathrm{H}_{2} \mathrm{O}_{2}$. It is possible that p62 could interact with Keap1 to regulate Nrf2 entry to the nucleus, as well as act downstream of ARE. This evidence indicates that cisplatin-resistant cells effectively avoid oxidative stress-induced apoptosis as a result of p62 efficiently regulating the Keap1-Nrf2-ARE system to mediate cisplatin resistance in HOCCs. Therefore, p62 represents a candidate therapeutic target for the improvement of cisplatin efficacy.

\section{Acknowledgements}

This study was funded by the National Natural Science Foundation of China (nos. 81201268, 81272876 and 81372793), the Postdoctoral Science Foundation of China (no. 2013M540256) and the Fundamental Research Project of Jilin University (no. 450060481216).

\section{References}

1. Goff BA, Mandel LS, Drescher CW, et al: Development of an ovarian cancer symptom index: possibilities for earlier detection. Cancer 109: 221-227, 2007.

2. Shank JJ, Yang K, Ghannam J, et al: Metformin targets ovarian cancer stem cells in vitro and in vivo. Gynecol Oncol 127 . 390-397, 2012.

3. Pils D, Bachmayr-Heyda A, Auer K, et al: Cyclin E1 (CCNE1) as independent positive prognostic factor in advanced stage serous ovarian cancer patients - a study of the OVCAD consortium. Eur J Cancer 50: 99-110, 2014.

4. Gottesman MM: Mechanisms of cancer drug resistance. Annu Rev Med 53: 615-627, 2002. 
5. Florea AM and Busselberg D: Cisplatin as an anti-tumor drug: cellular mechanisms of activity, drug resistance and induced side effects. Cancers 3: 1351-1371, 2011.

6. Galluzzi L, Senovilla L, Vitale I, et al: Molecular mechanisms of cisplatin resistance. Oncogene 31: 1869-1883, 2012.

7. Cho JM, Manandhar S, Lee HR, et al: Role of the Nrf2-antioxidant system in cytotoxicity mediated by anticancer cisplatin: implication to cancer cell resistance. Cancer Lett 260: 96-108, 2008.

8. Hall MD, Handley MD and Gottesman MM: Is resistance useless? Multidrug resistance and collateral sensitivity. Trends Pharmacol Sci 30: 546-556, 2009.

9. Ruiz S, Pergola PE, Zager RA, et al: Targeting the transcription factor Nrf2 to ameliorate oxidative stress and inflammation in chronic kidney disease. Kidney Int 83: 1029-1041, 2013.

10. Clarke HJ, Chambers JE, Liniker E, et al: Endoplasmic reticulum stress in malignancy. Cancer Cell 25: 563-573, 2014.

11. Kim HJ, Lee JH, Kim SJ, et al: Roles of NADPH oxidases in cisplatin-induced reactive oxygen species generation and ototoxicity. J Neurosci 30: 3933-3946, 2010

12. Zhong YY, Chen HP, Tan BZ, et al: Triptolide avoids cisplatin resistance and induces apoptosis via the reactive oxygen species/nuclear factor-kappaB pathway in SKOV3 platinumresistant human ovarian cancer cells. Oncol Lett 6: 1084-1092, 2013.

13. Taguchi K, Motohashi H and Yamamoto M: Molecular mechanisms of the Keap1-Nrf2 pathway in stress response and cancer evolution. Genes Cells 16: 123-140, 2011.

14. Zhang DD: The Nrf2-Keap1-ARE signaling pathway: the regulation and dual function of Nrf2 in cancer. Antioxid Redox Signal 13: 1623-1626, 2010.

15. Pi J, Zhang Q, Fu J, et al: ROS signaling, oxidative stress and Nrf2 in pancreatic beta-cell function. Toxicol Appl Pharmacol 244: 77-83, 2010.

16. Moscat J, Diaz-Meco MT and Wooten MW: Signal integration and diversification through the p62 scaffold protein. Trends Biochem Sci 32: 95-100, 2007.
17. Mazure NM and Pouyssegur J: Hypoxia-induced autophagy: cell death or cell survival? Curr Opin Cell Biol 22: 177-180, 2010.

18. Yu H, Su J, Xu Y, et al: p62/SQSTM1 involved in cisplatin resistance in human ovarian cancer cells by clearing ubiquitinated proteins. Eur J Cancer 47: 1585-1594, 2011.

19. Lau A, Zheng Y, Tao S, et al: Arsenic inhibits autophagic flux, activating the Nrf2-Keap1 pathway in a p62-dependent manner. Mol Cell Biol 33: 2436-2446, 2013.

20. Lau A, Wang XJ, Zhao F, et al: A noncanonical mechanism of Nrf2 activation by autophagy deficiency: direct interaction between Keap1 and p62. Mol Cell Biol 30: 3275-3285, 2010.

21. Yang Y1, Parsons KK, Chi L, et al: Glutathione S-transferasemicro1 regulates vascular smooth muscle cell proliferation, migration, and oxidative stress. Hypertension 54: 1360-1368, 2009.

22. Ma Q: Role of nrf2 in oxidative stress and toxicity. Annu Rev Pharmacol Toxicol 53: 401-426, 2013.

23. Sarkaria JN, Schwingler P, Schild SE, et al: Phase I trial of sirolimus combined with radiation and cisplatin in non-small cell lung cancer. J Thorac Oncol 2: 751-757, 2007.

24. Kelland L: The resurgence of platinum-based cancer chemotherapy. Nat Rev Cancer 7: 573-584, 2007.

25. Agarwal R and Kaye SB: Ovarian cancer: strategies for overcoming resistance to chemotherapy. Nat Rev Cancer 3: 502-516, 2003.

26. Tummala MK and McGuire WP: Recurrent ovarian cancer. Clin Adv Hematol Oncol 3: 723-736, 2005

27. Kensler TW, Wakabayashi $\mathrm{N}$ and Biswal S: Cell survival responses to environmental stresses via the Keap1-Nrf2-ARE pathway. Annu Rev Pharmacol Toxicol 47: 89-116, 2007.

28. Jaramillo MC and Zhang DD: The emerging role of the Nrf2Keap1 signaling pathway in cancer. Genes Dev 27: 2179-2191, 2013. 